\title{
THE INSTITUTIONAL ENVIRONMENT AND COMMUNITIES OF SMALL FIRMS1
}

\section{Brigitte Späth}

\section{DOES SIZE MATTER?}

During the past decade a remarkable shift in attitude towards the status and role of small firms ${ }^{2}$ in economic and social development has occurred. Spurred by success stories about their job creation record, their ability to innovate, and to respond to crises, small firms are being contrasted with large firms and are increasingly being considered as the more efficient, flexible and dynamic business organisation. Expectations have been raised that small firm growth could become the key to a new dynamism in economic development, easing the stress of adjustment and providing a solution to mass unemployment. However, despite the rhetoric and an ever increasing amount of literature on the subject, actual understanding of the differences between small and large firms and their innate economic superiority is incomplete. Some of the expectations that have been raised extolling the merits of small firms may turn out to be as unfounded as the claims made for large firms in earlier years.

It is true that in some countries crisis itself has helped small firms to come (back) into business, compensating for the decline in both output and employment of large enterprises and the public sector. ${ }^{3}$ In many cases, small firms constitute the only source of new employment and serve as a safety net, especially for the poor urban population. Although the number and employment share of small firms have shown a remarkable increase, the experience is mixed in qualitative terms. The small firm sector is extremely heterogeneous: technologically backward sweat shops can be found alongside highly flexible and innovative small firms. While in some regions, countries and industries, small firms have achieved remarkable growth and competitiveness, in others they have stagnated and lagged behind the large firms in terms of their economic capacity, but also with regard to their social standard.
The co-existence of success and failure of small firms belies the view that it is the dimension of enterprises, as such, that is crucial to their performance. ${ }^{4}$ Given this heterogeneity, blanket generalisations about the development prospects of small firms are not tenable. The issue is not whether small firms have a growth and employment potential, but under what conditions and with what effects. The challenging questions the refore are: How can small firms meet the expectations of economically and socially viable development? In what way can economic targets, such as flexibility and efficiency, be reconciled with social objectives, such as employment creation, good pay and job quality? The objective of this article is to explore in particular the institutional environment which may hinder or enhance the pursuit of this double objective.

\section{LESSONS FROM EUROPEAN INDUSTRIAL DISTRICTS}

The premise of this article is that the main problem of small firms in LDCs is not their size but being isolated and powerless: small firms normally have fewer resources to call upon than large enterprises and hardly any possibilities for strategic behaviour, namely the ability to influence and shape their markets. It is suggested therefore, that small firms have to integrate themselves into a larger context of interfirm relations in order to overcome their resource deficit and to improve their political standing. This view is supported by a comprehensive review of small firm development in industrialised countries (Sengenberger et al 1990) and in Latin America (Späth 1992), and studies on interfirm cooperation (Pyke et al 1990), all of which have been recently undertaken within a concerted research effort coordinated by the International Institute for Labour Studies (IILS). These activities have been inspired and encouraged by the approach of flexible specialisation (Piore and Sabel 1984), which challenged

\footnotetext{
'This article summarizes some basic ideas of the author's work at the New Industrial Organisation Programme of the International Institute for Labour Studies, Geneva and also at a previous engagement in a research project undertaken at the University of Konstanz, Germany on 'International organisations, national development administrations, and small-scale industrial promotion in LDCs'.

${ }^{2}$ Throughout the text the term 'small firm' is taken broadly to include small-scale productive activities that are variously termed micro and small, and both informal or formal.

${ }^{3}$ For example, PREALC estimates for seven Latin American countries show that employment increased only 3.3 per cent between
}

1980 and 1987 in large private firms, whilst it reached 55.4 per cent in small firms, and 56.1 per cent in the urban informal sector. This phenomenon was even more striking during the severe recession of 1980-1983 when employment declined by 6.9 per cent in large firms, while increasing by 30 per cent in small firms and 24.1 per cent in the urban informal sector, PREALC, cited in ILO (1989:28).

${ }^{4}$ Little, Mazumdar and Page (1987) in their comparative analyses of small manufacturing enterprises in India and other developing countries found that firm size is insufficient as an economic variable, and that small producers are neither more nor less efficient than medium or large enterprises in the same industry (see Table 11-7: 195-96). 
the mass production paradigm and championed the viability of small-scale industrialisation. The purpose of this section of the article is to draw together the key features of a small firm variant of flexible specialisation - industrial districts ${ }^{5}$ - and to bring out some lessons for small firm development elsewhere. In Section 3, particular attention is given to what role the institutional environment plays in this process.

Promising clues as to how small firms can get organised, and how such cooperation yields (external) efficiencies and produces competitive and innovative ability are provided by the European example of industrial districts. The crucial characteristic is that the district is organised according to certain principles (Sengenberger and Pyke 1991); perhaps the most outstanding feature is that clusters of (mostly) small firms are linked through strong networks. Both the integration of small firms into a larger context of interfirm relations and close geographic proximity enhance division of labour among firms, cooperation, the spread of ideas and technical innovation, and a sense of group consciousness. The communities of small firms specialise in the same industrial sector in the sense of containing backward and forward linked activities contributing to the manufacturing of a family of products. This also includes the existence of the manufacturing and maintenance of capital goods, as well as various related technical and commercial services. A peculiar mixture of inter-firm cooperation and competition serves as an advantageous basis for continuous innovation, such as upgrading of machines, tools, production processes and also the product itself, and for meeting the competitive challenges through differentiated quality products, new markets and flexibility. The availability of a trained and adaptable workforce is a crucial component of this type of industrial organisation, as well as the existence of an entrepreneurial culture and dynamism which facilitates entry but also exit from business, close working relations and trust among entrepreneurs. Strong interest groups, self-help organisations and effective regional and municipal authorities back up such industrial organisation.

This specific combination of economic, social and institutional arrangements has provided the conditions in which small firms can achieve the economies of scale and scope normally enjoyed by large firms and which enables them to compete successfully in both national

${ }^{5}$ Although particularly prominent in Italy, industrial districts are also to be found in other European countries. See Pyke and Sengenberger (1992).

'Schmitz (1990) has coined the notion of 'collective efficiency' to bring out that clustering facilitates efficiency and flexibility rarely attainable by individual firms. His contribution to this Bulletin brings out that such collective efficiency can come about both spontaneously through the market and as a result of collective action. ${ }^{7}$ Only recently have these important aspects become the focus of and international markets. ${ }^{6}$ Thus, small firms congregated in industrial districts have outperformed even large firms in many consumer goods, such as textiles, clothing, footwear, leather goods, and ceramics, and they have also excelled in precision engineering and machinery.

The economic success of the industrial district has come not from advantageous access to low cost factors of production - cheap labour, land or capital - but, rather from a particularly effective social and economic organisation based on small firms. This modus operandi drives the improvement of the overall performance of the business community, where each individual unit benefits from collective growth. Of course, the social underpinning of industrial districts has often grown over a long period of time, and is culturally rooted in traditions of family business - the metayage system in agriculture and craftsmanship. But it is important to recognise that these 'productive cultures' are linked to particular principles. The challenge is to find out whether these organisational principles or similar ones can be recreated elsewhere.

However, it is not assumed that the European-type industrial district can be directly transferred to the context of LDCs, and thus trying to add just another blue-print model, such as industrial estates, incubators, technology parks, etc., to already existing ones. Rather, what should be explored is whether the organisational principles inherent in these industrial districts can serve as a viable model for industrial development which effectively combines economic viability with social objectives in LDCs. However, for an adoption of the industrial district concept in LDCs, one has to be aware of the fact that some of the crucial differences between industrialised and developing countries are to be found in the institutional environment.

\section{THE INSTITUTIONAL ENVIRONMENT OF SMALL FIRMS IN LDCS}

Whether small firms perform well or not and, more importantly, whether they yield prospects for economic and socially viable development, is largely a question of how they are organised and in which political and institutional setting they operate. However, until recently, the institutional environment of small firms has been neglected in most studies about their development prospects. ${ }^{7}$ In the European context

attention. For example, (i) De Soto's (1989) study on institutional constraints for small enterprise development has had an important impact on approaching the small firm sector; (ii) a research project at the University of Konstanz (Germany) has been dealing with the admiñistrative constraints of promoting small enterprises (Assunção et al forthcoming; Elsenhans and Fuhr 1991); (iii) a research programme on relations between the informal sector, public authorities, and political power is currently under way at the OECD Development Centre under the programme 'Governance and Entrepreneurship'. 
small firms and, particularly, industrial districts have benefited from a relatively sympathetic national legal and regulatory framework, as well as from the existence of strong interest groups, self-help organisations and effective regional and municipal authorities, which have backed up the collective and cooperative organisation of the district (Pyke 1991). However, what still prevails in many developing countries is a legal and regulatory environment which is badly distorted, and an administrative and institutional setting which is hardly supportive and often discriminatory. This section draws out the institutional obstacles for small firms in LDCs. This is followed, in Section 4, by a discussion on how congregation could help small firms to improve their environment.

\subsection{Bias in macro-policy}

Most single enterprises are over-burdened in trying to master all business functions, particularly if they face an economic and institutional environment which has been conditioned by large private and/or state-owned enterprises. ${ }^{8}$ Many developing countries have pursued a strategy of accelerated industrialisation based on large-scale enterprises and capital intensity. Through credit policies, investment incentives, trade regulations, licensing, etc., macro-economic policy has favoured the establishment and growth of large firms. In the case of industrial regulations, the World Development Report (World Bank 1991:78) lists the following: a entry barriers, such as establishment and capacity licensing, exclusivity arrangements, and market reservation policies, often used to promote state enterprises and protect powerful interests; b exit barriers, such as weak enforcement or a lack of appropriate laws; $c$ price controls, ostensibly to protect consumers; d canalisation or confinement policies, which give only specific firms the right to buy and sell certain goods according to centralised guidelines and priorities; and e administratively regulated allocation of key resources, such as credit and even physical inputs. Substantial resources have been marshalled in the formation of mostly large-scale, public and private enterprises, and sometimes for the attraction of foreign direct investments. Thus, government programmes, regulations and incentives have been biased towards large firms and have essentially, although to a great degree inadvertently, discriminated against small firms, hampering competition and innovation.

\subsection{Centralised administration}

Policies, programmes, regulations and incentives are implemented by administrative institutions and authorities. In many developing countries bureaucracy has displayed a high degree of concentration and centralisation of resources and decision making, and has shown features of paternalism and clientialism. In the field of economic promotion, institutional performance is often poor and the steering capacity limited. This is particularly true at the regional and local level, since these administrative units are not usually sufficiently equipped with competent staff, resources and decision making authority. In fact, initiatives by local authorities to promote private sector development are often stifled by a centralised decision making process and lack of financial resources. ${ }^{9}$ As things stand, most regional and local authorities would not profit from local economic growth, since taxes generated in the area are usually transferred to the central administration. Even where, officially, institutional or legal reforms have been introduced, such as decentralisation or an adaptation of the legal framework, the administrative sub-structure is too weak to implement these reforms efficiently. ${ }^{10}$

\subsection{Red tape}

The immediate institutional environment for small firms is shaped by various authorities which play an important role on account of their regulatory function, such as enforcing municipal by-laws, health and environmental regulations and their development function, such as zoning, provision of infrastructure, or educational and training facilities. Procedures to comply with regulations, such as registration and taxation, and those necessary to benefit from government incentives, to import or export, or to obtain credit often go beyond the capacity of small firms. One example of the administrative and regulatory maze faced by enterprises is the procedures a firm has to follow to become a recognised business activity. According to Tokman (1991) these procedures are highly variable between countries, and even within one country, in terms of time and costs involved. A prominent example of excessive bureaucratic requirements for registration is Peru, where de Soto (1989) found that the time required to complete all the formalities necessary to start up an enterprise in Lima was 289 days. ${ }^{11}$ Thus, the process of formalisation is not

\footnotetext{
${ }^{8}$ Maldonado (1989:66) describes the principal weakness of small firms in developing countries as lying in: ' . . . their isolation or the ir lack of organisation on any appreciable scale. Bogged down in legal and administrative difficulties, they are left to wallow while the large enterprises are given every assistance the public authorities can afford'.

${ }^{9}$ Fuhr (1992) provides more detailed information on Latin America. Furthermore, there is often a lack of incentive for officials of regional and local institutions to take initiatives or risks, since these administrative levels do not often offer career prospects for the civil
}

\footnotetext{
service.

${ }^{10}$ See Sanders (1985) for the problems of implementing the Brazilian Micro-Enterprise Law.

${ }^{11}$ Another example was Brazil, where until the late 1970s small firms had to fulfil the same requirements as larger ones, with about 500 documents, signatures, and permits required to establish, maintain and liquidate a firm, (Sanders 1985: 3). According to Tokman (1991) these procedures to register an industrial enterprise now take about 44 working days in Brazil.
} 
only time consuming and costly, it also constitutes a barrier equivalent to a prohibition to operate legally. ${ }^{12}$ As long as the formalisation process is so cumbersome and does not entice immediate advantages, registration or legality will not be of priority importance to entrepreneurs. However, not being officially recognised as a business also implies insecurity. Such enterprises are often subject to diverse forms of harassment and may have to pay off various officials in order to stay in business. These firms are also unprotected by law in such matters as enforcement of contracts and property rights; moreover, they are deprived of access to technical assistance, credits and government incentives (ILO 1991; Tokman 1989).

\subsection{Institutional growth traps?}

In order to overcome the negative effects of broader policies for small producers, some countries have introduced special incentives and direct assistance programmes. A prominent example is India, which has developed an elaborate incentive structure favouring small firm development dating back to the 1950s. Another example is Brazil, where the Micro-Enterprise Law, passed in 1984, guarantees special treatment to small firms in such matters as registration, licensing, taxation, labour regulations, etc. (Sanders 1985; Piquet Caneiro 1992). However, even these well-intended interventions can be a mixed blessing. The Indian reservation policy for, presently, more than 800 items or product families, which are set aside for small producers, is increasingly being felt as constituting a barrier for improving the quality of products and technological upgrading of small firms ${ }^{13}$ Furthermore, exemptions from taxes and labour regulations for small firms decidedly limit their efforts at expansion. Cawthorne (1989) reports that these size barriers can be overcome, e.g. by setting up new small firms under the names of relatives of firm owners. Such an incentive structure has also induced large and medium enterprises to farm out part of their production. While in some cases such sub-contracting may grant mutual benefits, in others they may produce asymmetric exchange relations, in which large firms buffer costs and risks to the detriment of the small sub-contractors. ${ }^{14}$

Whereas such exemption and reservation policies can spur the set-up of new small enterprises, they also make it easier for inefficient small producers to survive.
Special incentives aimed at compensating for existing distortions are unlikely to be effective; they may even make things worse, e.g. by encouraging small firms to build their competitive advantage on cheap labour.

\subsection{The limits of direct support}

In many countries a number of special support programmes and institutions for small firm promotion have been set up, often with the assistance of international aid agencies. ${ }^{15}$ These institutions have largely been started to assist small firms to directly overcome their perceived weaknesses: $\mathbf{i}$ institutions have been created to cater for different services and training requirements; II industrial estates with a material infrastructure have been set up; and lii development and commercial banks have operated special credit schemes.

An evaluation of this type of foreign assistance has shown that most of these measures have been isolated interventions with significant limitations. ${ }^{16}$ In most cases only a small number of usually better-off and urban-centred enterprises have benefited. Furthermore, such institutions often have insufficient operational links with small firms and are unable to meet their fairly diversified needs, apply a rigid set of rules and regulations, and suffer from bureaucratic inertia and inability to innovate and take risks. In addition, there is rarely cooperation between the different support institutions - sometimes not even between the branches or extensions of the same institution - which causes a fragmentation of approaches and efforts, wastes human and financial resources, and obstructs inter-institutional complementarity. These institutions also become politicised and have a tendency to oblige some entrepreneurs through a system of patronage and clientalism. ${ }^{17}$

By creating specialised autonomous or semi-public institutions foreign donors originally sought to circumvent the structural weaknesses of public administration in developing countries. However, the advantages associated with this type of institution economic efficiency, problem-oriented organisation, as well as openness to public control - are diminished by the fact that these institutions, as a social sub-system, tend to reproduce the same administrative structures as the general system.

\footnotetext{
12 In some countries the mediation of specialised middlemen is required for even ordinary bureaucratic procedures. For example, Sanders (1985:3) reports that for this purpose Brazil has a professional class called despachantes, who know how to get documents and permits (including payments to public officials to facilitate matters), but for more complicated matters a lawyer is of ten needed.

${ }^{13}$ Little, Mazumdar and Page (1987:310-315); Kashyap (forthcoming); also support structures become politicised, Bauer and Elsenhans (1990).
} 


\section{THE NEED FOR SMALL FIRMS TO CONGREGATE}

Against a background of crisis resulting in dramatic declines in economic growth, employment and social conditions, many LDCs have adopted macro-economic stabilisation and structural adjustment programmes. In the course of such adjustments, some governments are examining the scope for amending, simplifying and streamlining regulations and administrative practices which currently present obstacles to private sector development. However, some laws and regulations are essential for the functioning of society and for the public interest. There is also no point in merely reprivatising across the board, improving price structures and liberalising the economy. The mere reliance on market forces and the strengthening of private sector development does not automatically benefit small firms. A redefinition of economic policy might again lead to dominance of large firms.

Policies must ensure that local resources are mobilised and that small firms are not discriminated against. Therefore, the question is not whether the State should involve itself in economic regulation, but rather, how it can undertake creative and effective policy-making to support private sector development. Up until now, a major problem for policy formulation, and also implementation, is that this process is of ten confined to a small group, lacking transparency and accountability. ${ }^{18}$ Small entrepreneurs have, as a rule, not been integrated into established interest groups, such as employer organisations, sectoral federations and associations, or Chambers of Commerce and Industry, and are thus excluded from any political bargaining process.

Any policy needs the support of the potential beneficiary if it is to be effective and produce permanent results. ${ }^{19}$ Since, during recent years, many countries have progressed towards more pluralist, participative and democratic societies, there is scope for new forms of interaction and consensus building in the political and institutional field to emerge, as well as a recognition that strategies and policies must be formulated in such a context.

Achieving sustainable small firm development is not only a matter of macro-economic policy formulation, it is also one of whether a bottom-up development can

${ }^{18}$ For example, with the persistence of mercantilist structures in Latin America large groups have for a long time been excluded from all policy formulation processes.

${ }^{19}$ The ILO report on the informal sector (1991:51 ff.) stresses that there is a necessity for a full commitment of the tripartite groups - governments, employers and workers - to apply a comprehensive strategy for the development of this sector. Employers'organisations tend to change their attitude towards the informal sector slowly, see Venkata Ratnam (1989)

${ }^{20}$ Schmitz (1992) observed this in the case of Baden-Württemberg, Germanv. take place. In fact, the strength of the industrial district concept, discussed in Section 2, becomes clearest at the local or regional level. Small firms usually have a much stronger commitment to their region or community than large firms, because the economic and social standing of the owner is more closely linked to local factors ${ }^{20}$ There are prospects for communities of small firms to contribute to the creation of regional and local virtuous circles. $^{21}$

A case in point is Latin America, where the process of democratisation seems to be closely linked with political and economic decentralisation, as well as participation at a local level. ${ }^{22}$ Regional and local authorities could create a conducive environment, and decentralised support institutions could provide the necessary real services, which would enhance collective efficiency. An organised and economically successful small firm sector in turn could strengthen these institutions to become effective development agents. Meaningful decentralisation requires that at least part of the tax revenue generated in the region would benefit the regional or local area. Thus, a flourishing and organised private sector could in fact support political and administrative reforms by strengthening politically and financially - regional and local authorities and institutions. Furthermore, through participation, they could exert the public control which is currently lacking, and thus, make these public authorities accountable to an extent most administrative rules may be unable to achieve.

However, the small firm sector is generally associated with high competitiveness and individualism. How can cooperative attitudes and trust develop in such a sector? There is evidence that there are already various forms of cooperation, division of labour and homogeneous value systems, which could serve as a basis for attaining collective organisations. For example, traditional savings and credit associations exist in many countries (Miracle et al 1980). Also, new forms of successful cooperations emerge: examples of successful collective actions in India are the Working Women's Forum (WWF) and the Self-Employed Women's Association (SEWA). ${ }^{23}$ The ILO also has first positive experiences with the organisations of artisans in French-speaking Africa (Maldonado 1989). Furthermore, examples of sectoral agglomerations of

${ }^{21}$ Fuhr (1992) elaborates this argument for Latin America.

${ }^{22}$ This was discussed in an OECD seminar on 'Local employnent initiatives: comparing the experience of OECD and Latin America', held in Valencia, 29-31 January 1990. It was also discussed as part of the joint IILS/ILAM conference on 'Small firms and development in Latin America', held in São Paulo, 28-31 March 1990. It is likely that this point will also be brought up in Africa in the course of the democratisation process.

${ }^{23}$ Both groups started off as a cooperative-type movement and are now registered as trade unions, see ILO (1991:47). Tendler (1989) mentions some more in her study on local non-governmental organisations in India 
small firms, which show features of ind ustrial districts, are known from Brazil, Ghana, India, Indonesia and Peru. ${ }^{24}$ The pivotal point to be made here is that promotional policy for small firms needs to go beyond treating the small firm as an isolated, or self contained entity, rather, it ought to be geared to a cluster or community of firms which strive for collective efficiency. Lessons drawn from the European example of successful small firm development indicate that where small firms congregate, they stand a better chance of overcoming their resource deficit and improving their political standing.

Indonesia, see Smyth (this Bulletin); and for Peru, see Villarán (1992).

${ }^{24}$ For Brazil see, for example, Schmitz (1990); Medeiros (1990); Marcovitch (1992); for Ghana, see Schmitz (ibid); Dawson (this Bulletin); for India, see Cawthorne (1989); Schmitz (ibid); for

\section{REFERENCES}

Assunção, P., Fuhr, H. and Späth, B., forthcoming, Internationale Organisationen, Entwicklungsverwaltungen und Kleingewerbeförderung in der Dritten Welt, Final Research Report SFB 221/A1, Nomos, Baden-Baden

Bauer, A. and Elsenhans, H., 1990, Structural Problems of Implementing Poverty Alleviation Programmes in the Third World, Konstanz, Amsterdam, (International Political Science Association) IPSA-Round Table Contribution

Bhatt, V. V., 1988, 'Financial institutions and technical consultancy services: the Indian experiment in smallenterprise promotion', fournal of Development Planning, No 18:63-82

Cawthorne, P., 1989, 'The labour process under amoebic capitalism: a case study of the garment industry in a South Indian town', paper presented at the workshop on 'Development and change of the labour process in the Third World and advanced capitalist countries' held at the Institute of Social Studies, The Hague, 14-15 April 1989

de Soto, H., 1989, The Other Path: The Invisible Revolution in the Third World, Harper \& Row, New York

Elsenhans, H. and Fuhr, H. (eds.), 1991, Administrations and Industrial Development: Case Studies of National and International Assistance Programmes for Small Enterprises in $L D C s$, National Book Organisation, New Delhi

Fuhr, H., 1987, 'Economic restructuring in Latin America: towards the promotion of small-scale industry', IDS Bulletin, Vol 18 No 3:49-53

-1992, 'Mobilizing local resources in Latin America: decentralisation, institutional reforms and small-scale enterprises', in B. Späth (ed.)

-and Späth, B., 1989, 'International organisations and smallscale industry promotion: genesis, implementation and evolution of a development policy concept', Labour and Society, Vol 14 No 3, July:213-228

ILO, 1989, World Labour Report No 4

-1991, 'The dilemma of the informal sector', International Labour Conference 78th Session, ILO, Geneva
Kashyap, S. P., forthcoming, 'Recent developments in the small-scale enterprise sector in India: economic and social aspects', Discussion Paper, International Institute for Labour Studies, Geneva

Little, I. M. D., Mazumdar, D. and Page, J. M., 1987, Small Manufacturing Enterprises: A Comparative Analysis of India and Other Economies, Oxford University Press for the World Bank, New York

Maldonado, C., 1989, 'The underdogs of the urban economy join forces', International Labour Review, Vol 128 No 1:65-84

Marcovitch, J., 1992, 'Technological innovation and small firms in Brazil', in B. Späth (ed.)

Medeiros, A. J., 1990, 'Les nouvelles technologies et la formation des pôles technologiques brésiliens', São Paulo, Centre de Documentation Universitaire Scientifique et Technique (CENDOTEC), mimeo

Miracle, M. P., Miracle, D. S. and Cohen, L., 1980, 'Informal savings mobilization in Africa', Economic Development and Cultural Change, Vol 28 No 4:701-724

Piore, M. and Sabel, C., 1984, The Second Industrial Divide: Possibilities for Prosperity, Basic Books, New York

Pyke, F., 1991, 'Upgrading industrial sectors: Creating an institutional framework', study prepared for INDUSTR/ILO, Geneva, mimeo

-and Sengenberger, W. (ed.), 1992, Industrial Districts and Local Economic Regeneration, Geneva, International Institute for Labour Studies

-Becattini, G. and Sengenberger, W. (eds.), 1990, Industrial Districts and Inter-firm Cooperation in Italy, Geneva, International Institute for Labour Studies

Sanders, T. G., 1985, 'Brazil's microbusiness law', UFSI Reports, No 26:1-6

Schmitz, H., 1990, 'S mall firms and flexible specialisation in developing countries', Labour and Society, Vol 15 No 3:257-281

-1992, 'Industrial districts: Model and reality in BadenWürttemberg', in F. Pyke and W. Sengenberger (eds.) 
Sengenberger, W., 1988, 'Economic and social perspectives of small enterprises', Labour and Society, Vol 13 No 3:249-259

-and Pyke, F., 1991, 'Small firm industrial districts and local economic regeneration: Research and policy issues', Labour and Society, Vol 16 No 1:1-22

-Loveman, G. W. and Piore, M. J. (eds.), 1990, The $R e^{-}$ emergence of Small Enterprises: Industrial Restructuring in Industrialised Countries, International Institute for Labour Studies, Geneva

Späth, B. (ed.), 1992, Small Firms and Development in Latin America, International Institute for Labour Studies, Geneva

Tendler, J., 1989, "What ever happened to poverty alleviation?' in World Development, Vol 17 No 7:1033-1044

Tokman, V. E., 1991, 'Informal sector in Latin America: from underground to legality', in G. Standing and V. E. Tokman, (eds.), Labour Market Issues and Structural Adjustment, ILO, Geneva

- 1989, 'Policies for a heterogeneous informal sector in Latin America', World Development, Vol 17 No 7:1067-1076

UNDP et al, 1988, Development of Rural Small Industrial Enterprises: Lessons from Experience, a joint study by UNDP, Government of the Netherlands, ILO, UNIDO, Vienna

Venkata Ratnam, C. S., 1989, 'Role of employers organisations in the informal sector', background paper for the ILO South Asian Employers' Symposium at Colombo, Sri Lanka, March 21-24 1989, ILO, Geneva

Villarán, F., 1992, 'Efficiency groups of small firms in Peru', in B. Späth (ed.)

World Bank, 1991, World Development Report, IBRD, Washington DC 